\title{
Radiological study of Os trigonum and its clinical significance
}

\author{
Mallikarjun Adibatti', Muthiah Pitchandi², Bhuvaneswari $\mathbf{V}^{3}$ \\ ${ }^{1}$ Associate Professor, Department of Anatomy, ${ }^{3}$ Professor and Head, Department of Radio-diagnosis, ESIC Medical \\ College and PGIMSR, ${ }^{2}$ Professor, Department of Radiology, Saveetha Medical College, Chennai, Tamil Nadu, India
}

Background: Os trigonum (OST) is commonly located on the posterior aspect of the talus. It occurs as a result of secondary ossification center failing to fuse with the lateral tubercle of the posterior process of the talus; its incidence varies between 2 and $25 \%$, and is more often bilateral. It occurs as an intra-articular Os, which is most often securely rooted to the lateral tubercle of the talus by a fibrocartilaginous synchondrosis. Aims and Objective: To determine the incidence, morphology, and distribution of Os Trigonum (OST). Materials and Methods: Retrospective 500 lateral foot radiographs view were studied to determine the incidence, morphology, and distribution of OST. Results: Incidence of OST in the present study was $6.6 \%$, with predominantly round or ovoid in shape. OST was located on the posterolateral aspect of the talus. Conclusion: OST can be one of the causative factor responsible for Flexor hallucis longus tendonitis, OST syndrome, which occur in plantarflexion of the ankle, leading to compression of the OST between the distal tibia and the calcaneus. Hence, knowledge regarding the incidence, morphology, and distribution of OST is important for the radiologist, orthopedic surgeons to arrive at a correct diagnosis, which aids in the management of cases presenting with complaints of posterior ankle pain.

Key words: Os trigonum; Os trigonum syndrome; Posterior ankle pain; Flexor hallucis longus tendonitis

\section{Access this article online}

Website:

http://nepjol.info/index.php/AJMS DOI: 10.3126/ajms.v12i12.39443

E-ISSN: 2091-0576

P-ISSN: 2467-9100

Copyright (c) 2021 Asian Journal of Medical Sciences

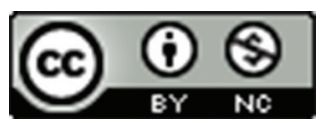

This work is licensed under a Creative Commons Attribution-NonCommercial 4.0 International License.

\section{INTRODUCTION}

Os trigonum (OST) is a foot ossicles which occurs due to failure of fusion of ossification center or development of additional center which is incidentally identified in routine radiographs. It is one of the normal variant found on the posterior aspect of talus; its incidence varies from 2 to $25 \%$ in the earlier studies. ${ }^{1-5}$ It can be triangular, round, or oval in shape, more often bilateral usually single in number but can be bipartite or multi partite and is best visualized on lateral foot radiographs. It is usually $<1 \mathrm{~cm}$ in size. Margins of OST are either smooth or serrated in appearance. ${ }^{4,6}$ When triangular it presents with three surfaces anterior, inferior, and posterior. The anterior surface articulate with the lateral tubercle of talus by fibrocartilaginous synchondrosis, while the inferior surface articulate with calcaneum and the posterior surface forms non-articular area and provides attachment to posterior talocalcaneal and posterior talofibular ligaments one must be familiar with such normal anatomical variants in order to prevent their misinterpretation and overtreatment in cases of trauma and ankle sprain. ${ }^{4}$

Ankle impingement is one of the causes of subacute to chronic ankle pain. In hyper plantar flexion OST can impinge on the posterior border of tibia which is more commonly seen in ballet dancers, athletes, and soccer players. OST syndrome or posterior ankle impingement (PAI) results from blunt foot trauma and is usually associated with pain and tenderness at the ankle joint. ${ }^{4-7}$

Knowledge regarding OST is important to identify the potential cause of posterior ankle pain and to decide on the conservative or surgical line of management. Hence, a radiographic study on OST was done to determine the incidence, morphology, and distribution of OST in the 
foot radiographs and has been reported for its clinical significance.

Aims and objectives

To determine the incidence, morphology, and distribution of OST.

\section{MATERIALS AND METHODS}

Consecutive 500 normal lateral foot radiographs of both sexes were selected using a convenient sampling method and incorporated in the study to determine the incidence, morphology, and distribution of OST. Descriptive analysis was applied and results were expressed in the form of average and percentage. The study was preapproved by the Institutional Ethics Committee for the final permission.

\section{Inclusion criteria}

All subjects belonging to any gender with age ranging from 12 to 80 years.

\section{Exclusion criteria}

Radiographs with incorrect patient positioning, foot deformity, fractures of metatarsal and tarsal bones were excluded from the study.

\section{RESULTS}

Out of 500 radiographs of the foot, 33 cases of OST were observed with varying shape and size, which accounts for $6.6 \%$ the incidence (Table 1). Shape of OST was predominantly round (Figure 1) or oval (Figure 2); being separated from the talus by a radiolucent line, with a well-corticated appearance and distinct margins. It was located posterolateral to the talus bone. Incidence of OST was more in males $(8.27 \%)$ compared to females $(4.7 \%)$ (Table 2).

\section{DISCUSSION}

Accessory ossicles of the foot are commonly confused for avulsion fractures of the foot, leading to misdiagnosis and overtreatment in cases of trauma. ${ }^{1,5,6}$ OST was first described in 1804 by Rosenmuller. ${ }^{2,7}$ OST is an accessory ossicle located posterolateral to talus; it has an incidence ranging from 2 to $25 \% .^{1-5}$ Incidence of OST was $6.6 \%$ (Table 1) among the study population, however Uygur et al., ${ }^{1}$ reported in his study an incidence of $15.4 \%$, which is comparatively higher than present study.

OST can be triangular, oval, or round in shape, they are best visualized on lateral radiographs, ${ }^{2,4}$ however, in the present study it was predominantly oval or round in shape. Incidence of OST was more in males $8.27 \%$ (22 males) compared to females 4.7\% (11 females) (Table 2) which correlates with an earlier study by Uygur et al., ${ }^{1}$ who has also reported a higher incidence in males $(55.3 \%)$ compared to females $(44.6 \%){ }^{1}$

PAI syndrome/OST syndrome can be caused due to various factors such as Stieda process fracture, an avulsion injury of the posterior talofibular ligament, or cartilaginous synchondrosis disruption, Flexor hallucis longus (FHL) tendonitis. It frequently occurs bilateral being common

\begin{tabular}{lccc} 
Table 1: Incidence of Os trigonum & \\
\hline & $\begin{array}{c}\text { No. of radiographs } \\
\text { with Os trigonum }\end{array}$ & $\begin{array}{c}\text { Absence of } \\
\text { Os trigonum }\end{array}$ & Total \\
\hline $\begin{array}{l}\text { Incidence of } \\
\text { Os trigonum }\end{array}$ & 33 & 467 & 500 \\
$\begin{array}{l}\text { Percentage of } \\
\text { Os trigonum }\end{array}$ & 6.6 & 93.4 & 100 \\
\hline
\end{tabular}

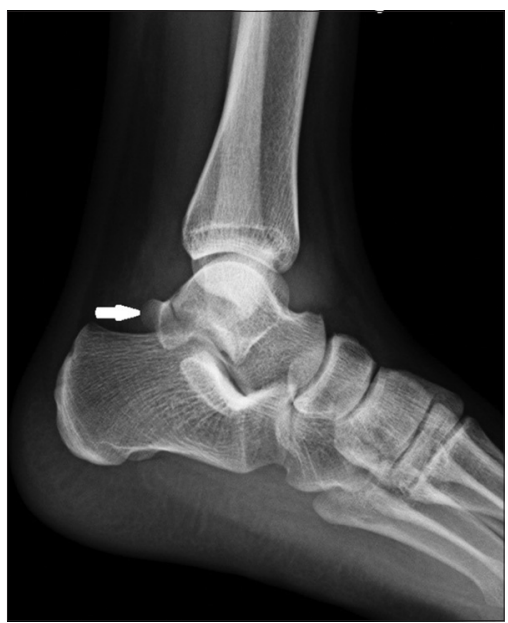

Figure 1: Lateral radiograph of the foot of 52 years male, arrow depicting a small rounded OST located posterolateral to the talus

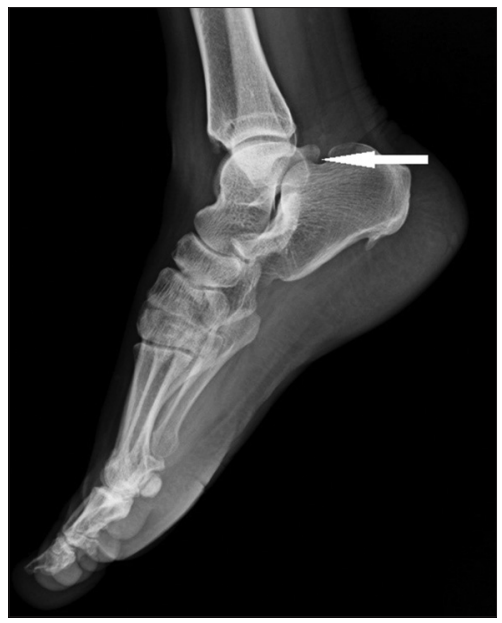

Figure 2: Lateral Radiograph of the foot of 40 years male, arrow indicating an oval-shaped OST 


\begin{tabular}{|c|c|c|c|}
\hline & $\begin{array}{l}\text { No. of radiographs } \\
\text { with Os trigonum (\%) }\end{array}$ & $\begin{array}{c}\text { Absence } \\
\text { of Os } \\
\text { trigonum (\%) }\end{array}$ & Total \\
\hline Male (266) & $22(8.27)$ & $244(91.72)$ & 266 \\
\hline Female (234) & $11(4.7)$ & $223(95.29)$ & 234 \\
\hline Total & $33(6.6)$ & 467 (93.4) & 500 \\
\hline
\end{tabular}

in soccer players, runners, and gymnasts, due to repeated plantar flexion of the ankle. ${ }^{6,8-12}$ It is predominantly symptomatic in men compared to women. ${ }^{3}$ Repetitive dorsiflexion of the foots, metatarsophalangeal joint, and plantarflexion of the ankle, can result in FHL tendonitis, tenosynovitis. ${ }^{9,12}$

OST resulting from failed fusion of secondary ossification center of lateral tubercle of the talus can be differentiated from avulsion fractures of the talus, by remarkably sharp edges and discontinuity of the cortical lining. Hyper plantarflexion of the ankle may result in posterior ankle fractures, which are commonly misdiagnosed and treated as simple ankle sprains, which can present with nutcracker sign. Painful OST syndrome should be considered as one of the differential diagnosis in patients presenting with recalcitrant posterolateral ankle pain. ${ }^{6,8}$

Painful OST can be effectively managed by conservative methods and appropriate physical therapy. Fractures of OST is very rare and can be efficiently treated with rest, ice packing, anti-inflammatory drugs, bracing, stretching, and strengthening exercises of the ankle and foot, in order to provide symptomatic relief, while increasing the range of movement and strength. If conservative treatment fails, excision of OST is indicated in symptomatic patients. ${ }^{6,8}$

OST is considered as a secondary ossification center which has failed to fuse with the posterior aspect of the talus. ${ }^{7}$ Being an intraarticular os it is connected to the lateral tubercle of the talus by fibrocartilaginous synchondrosis. ${ }^{6}$ Ossification center for OST appears between 8 and 13 years and usually fuses with the talus within 1 year with talus to form trigonal (Stieda) process. However, in 7-14\% of individuals, OST persists, which is very difficult to differentiate from avulsion fracture of the talus. ${ }^{4,13}$ Hence, OST must be borne in mind in treating patients with posterolateral ankle pain.

\section{Limitations of the study}

Although radiology being the initial mode of investigation, Ultrasonography, and MRI, can give a much clear view of the OST along with adjoining soft tissue mass and aid in the early diagnosis and management of posterior ankle pain.

\section{CONCLUSION}

Radiologists and surgeons must be aware of the ossicles of the foot such as OST so as to prevent their interpretation as fractures of tarsal bones or visa versa. OST is commonly misdiagnosed as peroneal tendinitis, avulsion fracture of talus in dancers presenting with posterolateral ankle pain. Hence, knowledge pertaining to the incidence, location, and morphology of OST can help in preventing misdiagnosis, it also aids in the early diagnosis of cases presenting with posterolateral ankle pain. By recognizing and treating this in symptomatic cases; progressive, debilitating deformity either conservatively or surgically, the surgeons will be able to resolve discomfort, improve joint function, and restore the quality of life of the patient.

\section{ACKNOWLEDGMENT}

We would like to thank the Department of Radio-diagnosis, ESIC Medical College and PGIMSR Chennai for assisting in data collection and aiding in the conduction of the study.

\section{REFERENCES}

1. Uygur E, Aktas B, Oz TT, Erinc S and Koc M. Prevalence of accessory bones of the foot in Turkish patients. JAREM. 2016;6:147-151.

https://doi.org/10.5152/jarem.2016.1085

2. Mellado JM, Ramos A, Salvadó E, Camins A, Danús M and Saurí A. Accessory ossicles and sesamoid bones of the ankle and foot: Imaging findings, clinical significance and differential diagnosis. Eur Radiol. 2003;13 Suppl 6:L164-L177.

https://doi.org/10.1007/s00330-003-2011-8

3. Coskun N, Yuksel M, Cevener M, Arican RY, Ozdemir H, Bircan $\mathrm{O}$, et al. Incidence of accessory ossicles and sesamoid bones in the feet: A radiographic study of the Turkish subjects. Surg Radiol Anat. 2009;31(1):19-24.

https://doi.org/10.1007/s00276-008-0383-9

4. Karasick $D$ and Schweitzer ME. The os trigonum syndrome: Imaging features. AJR Am J Roentgenol. 1996;166(1):125-129. https://doi.org/10.2214/ajr.166.1.8571860

5. Nwawka OK, Hayashi D, Diaz LE, Goud AR, Arndt W 3 rd, Roemer FW, et al. Sesamoids and accessory ossicles of the foot: Anatomical variability and related pathology. Insights Imaging. 2013;4(5):581-593.

https://doi.org/10.1007/s13244-013-0277-1

6. Reddy MC. Os trigonum syndrome-a case report. Int J Biomed Adv Res. 2015;6(1):60-63.

https://doi.org/10.7439/ijbar.v6i1.1564

7. Cerezal L, Abascal F, Canga A, Pereda T, Roberto GV, Luis PC, et al. MR imaging of ankle impingement syndromes. AJR Am J Roentgenol. 2003;181(2):551-559.

https://doi.org/10.2214/ajr.181.2.1810551

8. Heyer $\mathrm{JH}$ and Rose DJ. Os trigonum excision in dancers via an open posteromedial approach. Foot Ankle Int. 2017;38(1):27-35. https://doi.org/10.1177/1071100716665576 
9. Safer VU, Safer U and Kaya L. An unusual os trigonum syndrome case secondary to car accident: A case report. Middle East J Rehabil Health. 2016;3(2):e36719.

https://doi.org/10.17795/mejrh-36719

10. Hamilton WG. Foot and ankle injuries in dancers. Clin Sports Med. 1988;7(1):143-173.

https://doi.org/10.1016/S0278-5919(20)30965-0

11. Hamilton WG. Posterior ankle pain in dancers. Clin Sports Med.
2008;27(2):263-277.

https://doi.org/10.1016/j.csm.2007.12.002

12. Hamilton WG. Stenosing tenosynovitis of the flexor hallucis longus tendon and posterior impingement upon the os trigonum in ballet dancers. Foot Ankle. 1982;3(2):74-80.

https://doi.org/10.1177/107110078200300204

13. Chao W. Os trigonum. Foot Ankle Clin. 2004;9(4):787-796. https://doi.org/10.1016/j.fcl.2004.06.006

\section{Authors Contribution:}

MA- Concept and design of the study, reviewed the literature, preparation of the first draft of manuscript, Interpretation of the results, Coordination, statistical analysis, preparation of manuscript and revision of the manuscript; MP- Concept and design of the study; Interpretation of the results; preparation of manuscript and revision of the manuscript; BV- Concept and design of the study, Interpretation of the results, preparation of manuscript and revision of the manuscript.

Work attributed to:

ESIC Medical College and PGIMSR, K K Nagar, Chennai - 600 078, Tamil Nadu, India.

Orcid ID:

Dr. Mallikarjun Adibatti - (D) https://orcid org/0000-0002-3298-8071

Dr. Muthiah Pitchandi - (i) https://orcid.org/0000-0003-0322-3800

Dr. Bhuvaneswari V - (10 https://orcid.org/0000-0001-7558-9321

Source of Funding: None, Conflicts of Interest: None. 